\title{
Towards the asymmetric synthesis of bryostatin 1
}

\author{
Jef De Brabander and Maurits Vandewalle* \\ University of Gent, Department of Organic Chemistry, Laboratory for Organic Synthesis, \\ Krijgslaan, 281 (S.4), B-9000 GENT (Belgium)
}

\begin{abstract}
The construction of the fragments $\mathrm{C}_{1}-\mathrm{C}_{9} 3$ and $\mathrm{C}_{17}-\mathrm{C}_{27} 4 \mathrm{a}$ of the bryostatins in a enantioselective and highly diastereoselective fashion is described. The usefulness of the "chiron" approach is illustrated with the synthesis of these fragments from respectively D-pantolactone (6) and D-isobutyl lactate (14) as chiral templates.
\end{abstract}

The bryostatins have been isolated from the marine Bryozoan Bugula neritina and constitute a family of some 17 related macrocyclic lactones based on a polyacetate derived backbone ${ }^{1}$. Except for three $\mathrm{C}_{20}$ deoxy analogues they differ in the nature of the ester functions at $C_{7}$ and $C_{20}$. Bryostatin $1(1 b)$ possesses antineoplastic activity against lymphocytic leukemia and ovarian carcinoma ${ }^{2}$. Next to the first completed total synthesis of $1 \mathrm{c}$, by Masamune et al ${ }^{3}$, other groups have described the synthesis of fragments of the basic 20 -membered ring lactone ${ }^{4}$.

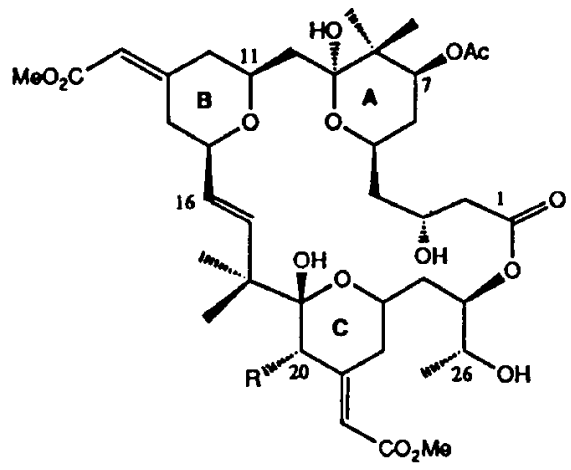

1. Bryostarin 11: $\mathrm{R}=\mathrm{H}$ 1b Bryostatin 1: $\mathrm{R}=\mathrm{O}_{2} \mathrm{C}(\mathrm{CH})_{4}\left(\mathrm{CH}_{2}\right)_{2} \mathrm{Me}$ 1c Bryostat in 7: $\mathrm{R}=\mathrm{OAC}$

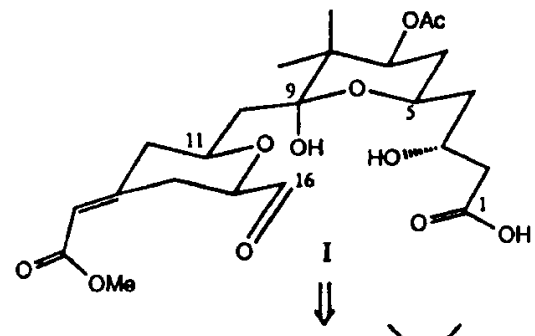

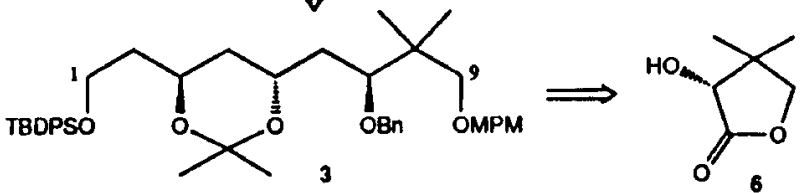

Scheme 1

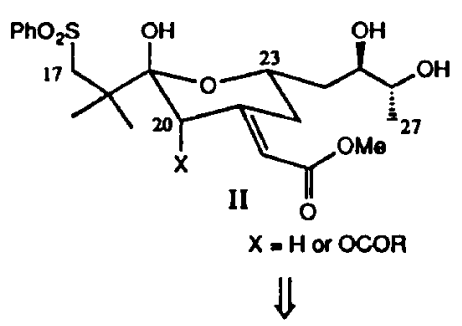

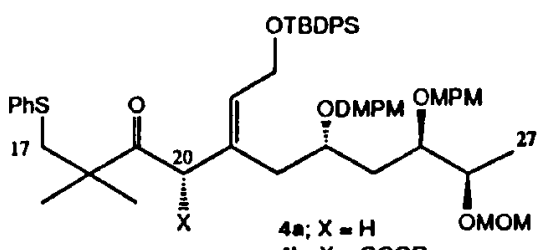

4b; $x=O C O R$

$\downarrow$

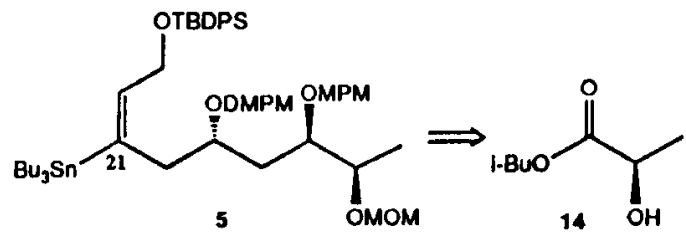

This paper describes out efforts towards the synthesis of the advanced intermediates 3 and $4 a$ of bryostatin 11 (1a) and illustrates the usefulness of the "chiron"5 approach combined with the power of single asymmetric induction 6 . Our retrosynthetic analysis is outlined in Scheme 1. Disconnection of the 
$\mathrm{C}_{16}-\mathrm{C}_{17}$ bond gave subunits $\mathrm{I}$ and II; the final step for assembling the skeleton will involve double bond formation via a Julia-Lythgoe reaction. 3,7 We plan to construct the northern-eastern part I via 3 and a $\mathrm{C}_{11}-\mathrm{C}_{16}$ fragment and to connect them via a keto-phosphonate thus providing $\mathrm{C}_{10}$. We have already reported on the synthesis of the tetrahydropyran ring $B\left(C_{11}-C_{16}\right)$ and on a model study for joining rings $A$ and B. ${ }^{6 a}$ The strategy for the construction of the southern fragment II $\left(C_{17}-C_{27}\right)$ centers around disconnection of the $\mathrm{C}_{20}-\mathrm{C}_{21}$ bond. The formation of this bond, via 5 and using Pier's 8 conjugate organostannyl cuprate addition method, provides control for the E-geometry of the double bond. Furthermore this strategy carries the potential for the synthesis of both the 20-desoxy and 20-oxy series.

\section{Synthesis of the $\mathrm{C}_{1}-\mathrm{C}_{9}$ fragment 3 (Scheme 2)}

Our second and succesfull approach involves the creation of $\mathrm{C}_{3}$ as a new stereogenic center during diastereoselective reduction of $\beta$-hydroxy ketone 12 . Moreover, it was anticipated that aldol reaction involving 11 and chiral $\beta$-alkoxy-aldehyde 10 , could induce chirality at $C_{5}$.

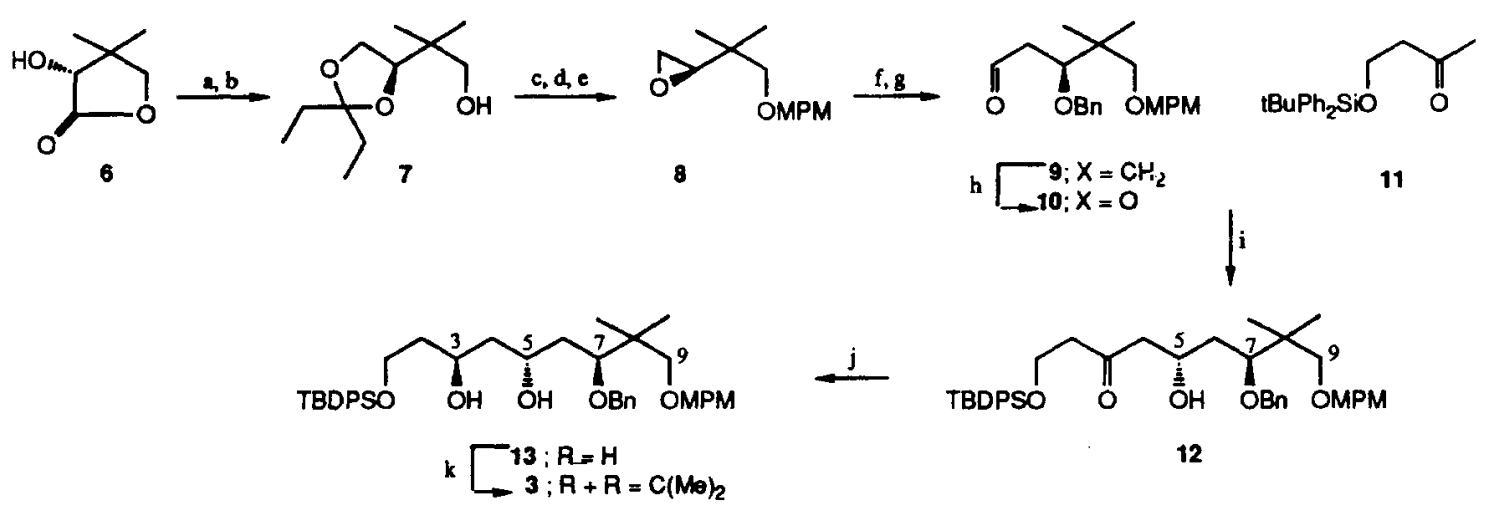

(a) $\mathrm{LiAlH}_{4}, \mathrm{THF}, 0^{\circ} \mathrm{C}$, reflux, $5 \mathrm{~h}$, r.t.; (b) 3-pentanone, PTSA, THF, reflux, $5 \mathrm{~h}$ (81\%, two steps); (c) t-BuOK, THF, then MPMCl, r.t., 12 h (94\%); (d) $10 \% \mathrm{HCl}-\mathrm{THF}$, r.t., $5 \mathrm{~h}(92 \%)$; (e) NaH, DMF-THF, r.t., $4 \mathrm{~h}$, then tosylimidazole, r.t., $2 \mathrm{~h}(92 \%)$; (f) $\left(\mathrm{CH}_{2}=\mathrm{CH}\right)_{2} \mathrm{CuCNLi}, \mathrm{Et}_{2} \mathrm{O}, 0^{\circ} \mathrm{C}, 30 \mathrm{~min}$ $\left(84 \%\right.$ ); (g) t-BuOK, THF, then $\mathrm{BnBr}$, r.t., $12 \mathrm{~h}$ (96\%); (h) i) $\mathrm{OsO}_{4}$, NMO, $\mathrm{H}_{2} \mathrm{O}-\mathrm{THF}$, r.t., $5 \mathrm{~h}$; ii) $\mathrm{Pb}(\mathrm{OAc})_{4}$, toluene, pyridine, r.t., $10 \mathrm{~min}\left(90 \%\right.$, two steps); (i) LDA, THF, $-78^{\circ} \mathrm{C}, 5 \mathrm{~min}$, then 18 , $-78^{\circ} \mathrm{C}$, 5 min then 17 (77\%); (j) $\mathrm{LiAl}(\mathrm{Ot} . \mathrm{Bu})_{3} \mathrm{H}$, LiI, $\mathrm{Et}_{2} \mathrm{O},-78^{\circ} \mathrm{C}$, (90\%); (k) $\mathrm{Me}_{2} \mathrm{C}(\mathrm{OMe}) 2$, Amberlyst-15, $\mathrm{CH}_{2} \mathrm{Cl}_{2}$, r.t., $30 \mathrm{~min}(94 \%)$.

\section{Scheme 2}

D-pantolactone (6) was selected as chiral template for the synthesis of 10 by virtue of the correct stereogenic $C_{7}$ flanked by a gem-dimethyl group. Aldol condensation between 10 and 11 led exclusively to the anti-diastereoisomer 12 as expected on the basis of a Cram-type transition state, involving $\beta$-chelation of the lithium cation with the benzyl ether oxygen atom?.

We faced the formation of the $\mathrm{C}_{3}$-stereogenic center with some confidence because stereoselective reduction of $\beta$-hydroxy ketones is well-documented. However, selection of an appropriate anti-selective $\beta$ hydroxy ketone reducing agent proved to be very troublesome. It is remarkable that reduction with the Saksena-Evans reagent ${ }^{10}$, known to be highly anti-selective, showed no selectivity. Only tri-t-butoxyaluminum hydride in the presence of lithium iodide ${ }^{11}$, finally induced a 17.6:1 ratio in favour of 13; this only when the reaction proceeded at $-78^{\circ} \mathrm{C}$.

The formation of this fully identified fragment 3 in $89 \%$ d.e. and $27 \%$ overall yield compares favourably with other described procedures 3,4 .

Synthesis of $\mathrm{C}_{17}-\mathrm{C}_{27}$ fragment $4 \mathrm{a}$ (Schemes 3 and 4)

The strategy for the synthesis of fragment $4 a$, a fully protected open form of the southern hemiacetal I, has already been outlined in Scheme 1. The starting material for $5\left(C_{21}-C_{27}\right)$ is $D$-isobutyl lactate which is, in contrast to the ethyl or methyl ester of unnatural $D$ lactic acid, pricewize a reasonable chiral building block ${ }^{12}$ (Scheme 3). 


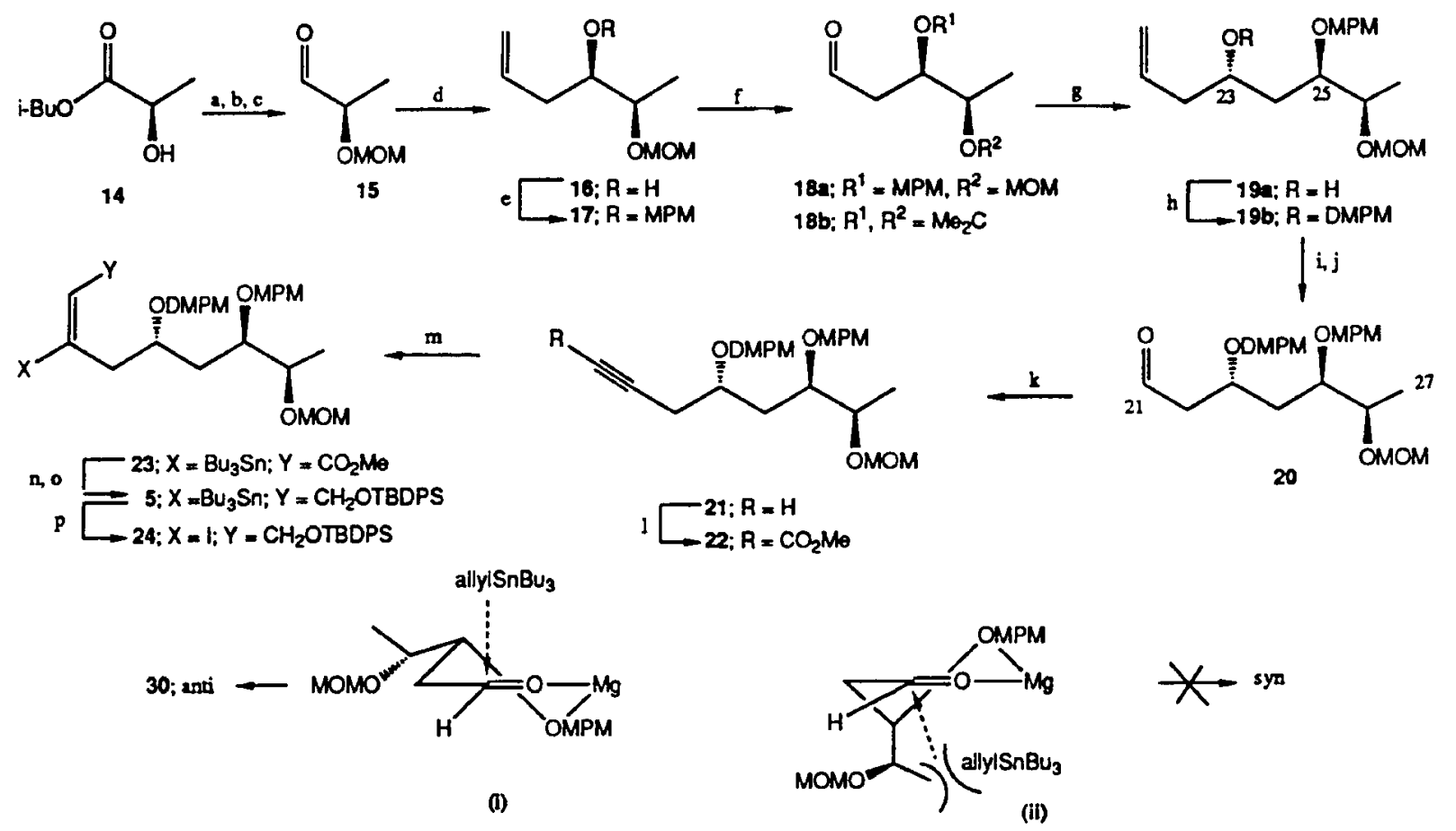

(a) MOMCl, DiPEA, $\mathrm{CH}_{2} \mathrm{Cl}_{2}$ (92\%); (b) $\mathrm{LiAlH}_{4}$, THF; $\mathrm{Na}_{2} \mathrm{SO}_{4} \cdot 10 \mathrm{H}_{2} \mathrm{O}$ (83\%); (c) (COCl)2, DMSO, $\mathrm{NEt}_{3}, \mathrm{CH}_{2} \mathrm{Cl}_{2},-78^{\circ} \mathrm{C}$; (d) allylSnBu$, \mathrm{MgBr}_{2} . \mathrm{Et}_{2} \mathrm{O}, \mathrm{CH}_{2} \mathrm{Cl}_{2},-78^{\circ} \mathrm{C} \rightarrow 0^{\circ} \mathrm{C}$ (60\% from 14); (e) t-BuOK, MPMCl, THF (69 \%); (f) $\mathrm{OsO}_{4}, \mathrm{NaIO}_{4}$, THF, $\mathrm{H}_{2} \mathrm{O}$ (70 \%); (g) allylSnBu3, $\mathrm{MgBr}_{2} . \mathrm{Et}_{2} \mathrm{O}$, $\mathrm{CH}_{2} \mathrm{Cl}_{2},-78^{\circ} \mathrm{C} \rightarrow 0^{\circ} \mathrm{C}(97 \%)$; (h) $\mathrm{t}-\mathrm{BuOK}$, DMPMBr, THF (79 \%); (i) OsO $\mathrm{O}_{4}, \mathrm{NMO}$, acetone (81 \%); (j) $\mathrm{NaIO}_{4}, \mathrm{Bu}_{4} \mathrm{NBr}, \mathrm{CH}_{2} \mathrm{Cl}_{2}, \mathrm{H}_{2} \mathrm{O}(92 \%)$; (k) (MeO) ${ }_{2} \mathrm{P}(\mathrm{O}) \mathrm{CHN}_{2}, \mathrm{t}-\mathrm{BuOK}$, THF, $-78^{\circ} \mathrm{C} \rightarrow-20^{\circ} \mathrm{C}$ (quant.); (l) $\mathrm{ClCO}_{2} \mathrm{Me}$, n-BuLi, THF $(95 \%)$; (m) Bus SnCu.Me2 S.LiBr, THF, $-78^{\circ} \mathrm{C}, 1.7$ eq. MeOH $(80 \%)$; (n) DIBAH, Et $2 \mathrm{O},-78^{\circ} \mathrm{C} \rightarrow-0^{\circ} \mathrm{C}(95 \%)$; (o) TBDPSCl, imidazole, DMAP, $\mathrm{CH}_{2} \mathrm{Cl}_{2}(95 \%)$; (p) $\mathrm{I}_{2}, \mathrm{CH}_{2} \mathrm{Cl}_{2}$ (quant.).

\section{Scheme 3}

We anticipated a diastereoselective construction of the $\mathrm{C}_{25}$ - and $\mathrm{C}_{23}$-stereogenic centers initially induced by the lactate chirality. The intermediate aldehyde 25 could not be purified (distillation or chromatography) without decomposition and was used as such in the 1,2-chelation-controlled allylation ${ }^{13}$ which led to the single diastereoisomer 16 in $60 \%$ overall yield.

Oxidative cleavage of the double bond, gave aldehyde 20 which upon 1,3-chelation-controlled allylation gave exclusively in $97 \%$ yield the 23 -anti-epimer 19 . This complete selectivity results from the preferred stereoelectronically controlled addition on chelate (i) versus (ii). This result sharply contrasts with the low diastereoselectivity, under identical conditions, observed for the corresponding acetonide 29b (synanti $2.5: 1$ ) which is probably due to the fact that each acetal oxygen atom can be involved in the chelation. The complete diastereoselective construction of the 23 and 25 stereogenic centers in this $C_{21}-C_{27}$ fragment compares favourably with reported results $3 \mathrm{~b}, 4 \mathrm{bc}$.

Having achieved the first goal we now faced the formation of acetylenic ester 22 from aldehyde 20. A number of methods are described to construct this structural unit via homologation of an aldehyde. Extensive experimentation was needed before we finally observed that the Seyferth reagent, dimethyl diazomethyl phosphonate ${ }^{14}$, produced 21 in quantitative yield; subsequent formation of 22 was uneventful.

Conjugate organostannyl cuprate addition 8 on 22 led to the E-isomer 23, subsequent reduction of the carboxyl group and silyl ether formation gave the key intermediate 5 .

The $C_{17}-C_{20}$ fragments 25 and 26 were also obtained from D-pantolactone 6. Although the stereogenic center in 6 is destroyed, it carries the potential for diastereocontrolled formation of $\mathrm{C}_{20}$ in an eventual synthesis of $\mathbf{4 b}$. 
Finally, the $\mathrm{C}_{20}-\mathrm{C}_{21}$ bond formation was undertaken. Reaction of the mixed higher order cuprate (from iodide 24) with epoxide 25 led, albeit in low yield, to 29, next to a substantial amount of reduced E-alkene (cf. 24 but $X=H$ ). Although, we plan to oxidize the 19-hydroxyl group subsequently to $C_{16}-C_{17}$ coupling, we checked whether this can be performed without concomitant double bond shift to the 20-21 position. Oxidation of 27 led quantitatively to $4 a$.
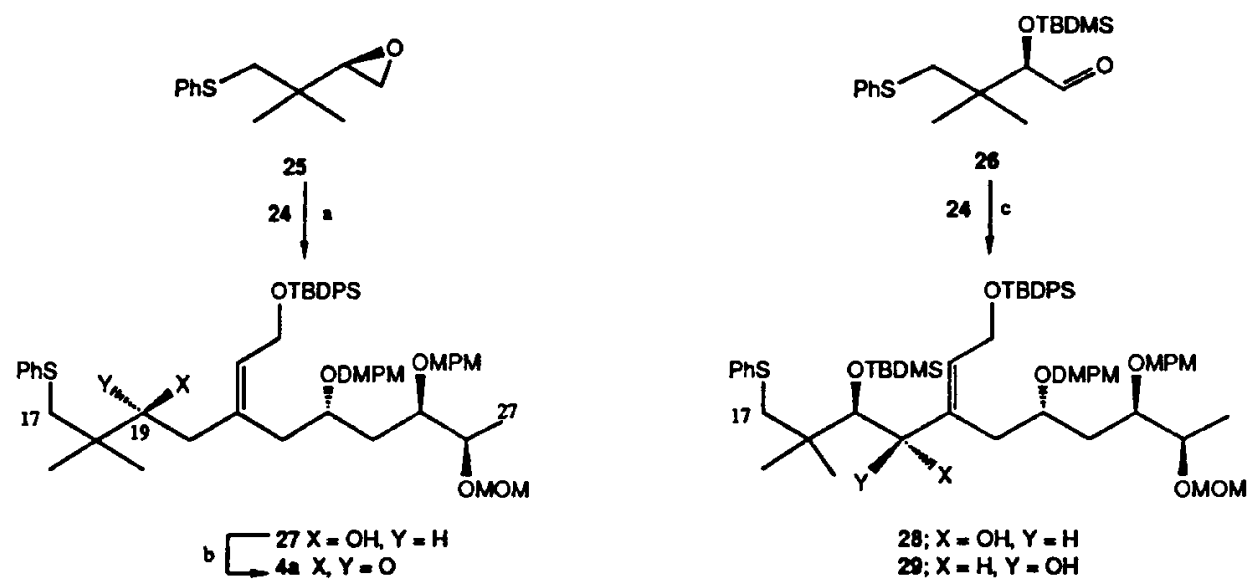

(a) 24, t-BuLi (2 eq.), Et ${ }_{2} \mathrm{O},-78^{\circ} \mathrm{C}, 30 \mathrm{~min}$; 2-thienylCuCNLi, THF, 41 (1.5 eq), $\mathrm{BF}_{3} . \mathrm{Et}_{2} \mathrm{O}$ (1.5 eq), $4 \mathrm{~h},-78^{\circ} \mathrm{C}$ (29\%); (b) $\mathrm{SO}_{3}$-pyridine, DMSO, $\mathrm{NEt} 3, \mathrm{CH}_{2} \mathrm{Cl}_{2}$, rt (100\%); (c) 24, t-BuLi (2 eq), THF, $-78^{\circ} \mathrm{C}, 1 \mathrm{~h} ; 43(1.2 \mathrm{eq}), 3 \mathrm{~h}(50 \%)$.

\section{Scheme 4}

Reaction of the anion derived from 24 with 26 led to 28 and 29 (2:1 separable mixture); this result indicated that the anticipated influence of the $\alpha$-stereogenic center in 26 is not operating with the expected degree of diastereoselectivity as predicted by the Anh-Eisenstein model; 29 is a precursor for $\mathbf{4 b}$ and for 20-oxy-bryostatins. However better stereocontrol is needed; further work is in progress.

Acknowledgements. We thank the "NFWO" and the "Ministerie voor Wetenschapsbeleid" for financial assistance to the laboratory.

\section{References}

1. Pettit, G.R.; Day, J.F.; Hartwell, J.L.; Wood, H.B. Nature 1970, 227,962.

2. Pettit, G.R.; Gao, F.; Sengupta, J.M.; Coll, J.C.; Herald, C.L.; Doubek, D.L.; Schmidt, J.M.; Van Camp, J.R.; Rudloe, J.J.; Nieman, R.A. Tetrahedron 1991, 47, 3601, and references cited therein.

3. (a) Blanchette, M.A.; Malamas, M.S.; Nantz, M.H.; Roberts, J.C.; Somfai, P.; Whritenour, D.C.; Masamune, S.; Kageyama, M.; Tamura, T.J.Org. Chem. 1989, 54, 2817. (b) Masamune, S. Pure Appl. Chem. 1988, 60, 1587. (c) Kageyama, M.; Tamura, T.; Nantz, M.H.; Roberts, J.C.; Somfai, P.; Whritenour, D.C.; Masamune, S. J. Am. Chem. Soc. 1990, 112, 7407.

4. (a) Evans, D.A.; Carreira, E.M. Tetrahedron Lett. 1990, 31, 4703. (b) Evans, D.A.; GauchetPrunet, J.A.; Carreira, E.M.; Charette, A.B. J. Org. Chem. 1991, 56, 741. (c) Roy, R.; Rey, A.W.; Charron, M.; Molino, R. J. Chem. Soc., Chem. Commun. 1989, 1308. (d) Roy, R.; Rey, A.W. Synlett. 1990, 448. (e) Munt, S.P.; Thomas, E.J. J. Chem. Soc., Chem. Commun. 1989, 480. (f) Ohmori, K.; Suzuki, T.; Miyazawa, K.; Nishiyama, S.; Yamamura, S. Tetrahedron Lett. $1993,34,4981$.

5. Hanessian, S. Total Synthesis of Natural Products : The "Chiron" Approach, Pergamon Press 1983.

6. (a) De Brabander, J.; Vanhessche, K.; Vandewalle, M. Tetrahedron Lett. 1991, 32, 2821. (b) De Brabander, J.; Vandewalle, M. Synlett 1994, 4, 231. (c) De Brabander, J.; Vandewalle, M. Synlett $1994,8,855$.

7. Julia, M. Pure Appl. Chem. 1985, 57, 763, see also ref. 3c.

8. Piers, E.; Morton, H.E. J. Org. Chem. 1980, 45, 4263.

9. See also Masamune, S.; Choy, W. Aldrichim. Acta 1982, 15, 47.

10. Evans, D.A.; Chapman, K.T. Tetrahedron Lett. 1986, 27, 5939. Saksena, A.K.; Mangiaracina, P. Tetrahedron Lett. 1983, 24, 273.

11. Mori, Y.; Suzuki, M. Tetrahedron Lett. 1989, 30, 4383. Iguchi, S.; Nakai, H.; Hayashi, M.; Yamamoto, H. J. Org. Chem. 1979, 44, 1363.

12. Available from Fluka Chemic AG.

13. Keck, G.E.; Abbott, D.E.; Boden, E.P.; Elholm, E.J. Tetrahedron Lett. 1984, 25, 3927.

14. (a) Seyferth, D.; Marmor, R.S.; Hilbert, P. J. Org. Chem. 1971, 36, 1379. (b) Gilbert, J.C.; Weerasooriya, U. J. Org. Chem. 1979, 44, 4997. (c) Gilbert, J.C.; Weerasooriya, U. J. Org. Chem. 1982, 47, 1837. 